\title{
Eurycnemus v. d. Wulp (Diptera, Chironomidae) newly recorded in China
}

\author{
L. Li, ${ }^{1}$ H. Tang ${ }^{2}$ \\ ${ }^{1}$ Research Centre of Hydrobiology, and ${ }^{2}$ Institute of Groundwater and Earth Science, Jinan University, Guangzhou, China
}

\begin{abstract}
Pharate male, pupa and larva of Eurycnemus cf. nozakii Kobayashi 1998 are described based on the associated material collected from Liaoning Province. This is the first record of this genus in China. The Chinese species is distinctly smaller than the Japanese E. nozakii at all stages, which can be separated from congeners by the presence of hind tibial comb and the absence of basal strong seta on the gonostylus in the male, some differences are also found in the immature stage, which suggest an independent new species rather than the true E. nozakii. Detailed differences are compared among similar taxa from Japan, Russian Far East and China. Pupal exuviae collected from Fujian and Yunnan Provinces were also examined, which can be separated from the above species by the short male genital sac. Because of few different characters at the immature stage among these similar taxa from a wide range, the possible high diversity within this genus is suspected. Based on the current knowledge, the generic diagnosis is emended.
\end{abstract}

Correspondence: Hongqu Tang, Institute of Groundwater and Earth Science, Jinan University, Guangzhou, 510632, China.

E-msil: townningt@gmail.com

Key words: Eurycnemus, first record, new species, emendation, China

Acknowledgements: We thank Mr. Changbing Duan for providing the invaluable material. This work was supported by the National Natural Science Foundation of China (No. 41672346, 31100389). Special thanks to Prof. Evgeniy A. Makarchenko for translating some Russian reference and discussion about the status of Russian Eurycnemus, also to Dr. Masaru Yamamoto for his invaluable suggestions.

Contributions: the authors contributed equally.

Conflict of interest: the authors declare no potential conflict of interest.

Received for publication: 9 October 2017.

Accepted for publication: 12 November 2017.

CC Copyright L. Li and H. Tang, 2017

Licensee PAGEPress, Italy

Journal of Entomological and Acarological Research 2017; 49:7129

doi:10.4081/jear.2017.7129

This article is distributed under the terms of the Creative Commons Attribution Noncommercial License (by-nc 4.0) which permits any noncommercial use, distribution, and reproduction in any medium, provided the original author(s) and source are credited.

\section{Introduction}

Genus Eurycnemus v. d. Wulp 1874 is a small genus within the Brillia group, which is represented by only two species in the world, i.e., E. crassipes (Meigen in Panzer, 1810) from Europe and E. nozakii Kobayashi, 1998 from Japan (Murray \& Ashe, 1981; Kobayashi, 1998; Ashe et al., 2000; Andersen et al., 2013). The previously reported Russian population of $E$. nozakii may be a new species (Makarchencko EA, pers. commun.). The immature stage is ectoparasitic on prepupa and pupa of caddisflies, which received extensive attention in recent years (Ashe et al., 2000; Hayashi \& Kobayashi, 2000; Ashe et al., 2015). The fat white body, relative small coniform head capsule and the elongated anterior prolegs in the larva, together with the anterior chitinized thoracic projection in the pupa allow separation from other related genera. In the neighboring regions of China, the host of the only recorded species $E$. nozakii is a goerid caddisfly - Goera japonica Banks, 1906, which has not yet been recorded in China. However, a sibling caddisfly species, G. interrogationis Botosaneanu, 1970 is common in the northeast part of China (Yang et al., 2003). These evidences suggest the possibility that Eurycnemus species is present in China.

In this paper, based on the associated materials collected from Liaoning province, we described the pharate male, pupa and larva under the name of $E$. cf. nozakii, representing a different species to the true E. nozakii. Since there is no well-preserved male, the exact species status is still unresolved. In addition, two similar pupal exuviae collected from Fujian and Yunnan Province are reported.

\section{Material and methods}

Specimens were slide-mounted in Euparal. Descriptions of morphological characters are based on slide-mounted specimens except when otherwise stated. Body coloration is based on specimens preserved in alcohol. Morphological terminology and abbreviations follow Sæther (1980). The number of observations (n) is given at the beginning of the species description, except when otherwise indicated in parenthesis. Measurements and counts are given as ranges, followed by the means.

All the specimens examined here are deposited in the Institute of Groundwater and Earth Science, Jinan University, China.

\section{Taxonomy}

Eurycnemus v. d. Wulp 1874

Diagnosis. The specimens examined conform in most diagnostic 
features to the generic description for adult, pupa and larva (Cranston et al., 1983, 1989; Coffman et al., 1986; Andersen et al., 2013). Based on the material described below, the generic diagnosis for Eurycnemus should be amended as follows.

MALE. Wing membrane with long and extensive dark macrotrichia, distinct bands present (E. nozakii, E. cf. nozakii) or absent (E. crassipes). Hind tibial comb present (E. cf. nozakii) or absent (E. crassipes, E. nozakii). A small and low tubercle with a seta present on the inner part of apical lobe of gonostylus. A rather long and strong basal seta present in the basal stem of gonostylus (before the lobe fork) (E. nozakii) or absent (E. crassipes, E. cf. nozakii).

PUPA. Tergites II-VII/VIII with long posterior spine. Conjunctive T II/III always with spinules, spinules in the conjunctive T III/IV, T V/VI-VI/VII varied in different species. Anal lobe with 4-7 strong long broad anal macrosetae and usually 1-2 shorter macrosetae, inner margin with or without setae. Male genital sac on the dorsal surface, subequal in length or slightly beyond the anal lobe.

LARVA. Premandible with 2 apical and 0-1 pale basal tooth. Mandible with seta interna (E. crassipes, E. cf. nozakii, E. sp. FE) or not (E. nozakii). Mentum with 3 median teeth and 5 pairs of lateral teeth. The first lateral teeth set off from three median teeth clearly. Centre median mental teeth simple or with further subdivisions, usually lower than outermost median teeth. Ventromentum clearly present (E. nozakii, E. cf. nozakii) or vestigial (E. crassipes, $E$. sp. FE). Seta submenti posterior clearly to the base of mentum. Anal seta normally simple, seldom bifurcated in some individuals (E. nozakii). Procercus sclerotized laterally (E. cf. nozakii) or normal (E. crassipes, E. nozakii).

Eurycnemus cf. nozakii Kobayashi, 1998

Eurycnemus sp., Kobayashi, 1993: 401; 1995: 317.

Eurycnemus nozakii Kobayashi, 1998: 109; Hayashi \& Kobayashi, 2000: 292.

Pharate male $(\mathrm{n}=1)$.

Total length $7.5 \mathrm{~mm}$. Body length $5.5 \mathrm{~mm}$. Wing pads $2 \mathrm{~mm}$.

COLORATION. Head, abdomen and legs brownish. Eye dark brown. Wing with 2 distinct dark and broad crossbands in the middle and apical $2 / 5$, slightly 2 pale areas in the basal and sub-middle section. HEAD. Terminal flagellomere length $950 \mu \mathrm{m}$. AR 2.11. Temporals 43, including 20 inner verticals, 19 outer verticals and 4 posterior verticals. Clypeal with 66 setae. Palpomere lengths $(\mu \mathrm{m}): 50 ; 72.5$; 210; $190 ; 165$.

THORAX. Thoracic setae is hard to discern in present material since most parts is covered by the pupal skin.

WING. Enclosed by the wing pad, with numerous setae in the membrane. Squama with ca. 40 setae. VR ca. 1.20.

LEGS. Fore tibia with one spur, $110 \mu \mathrm{m}$ long; two spurs of mid tibia $90 \mu \mathrm{m}$ and $110 \mu \mathrm{m}$ long, respectively; two spurs of hind tibia 110 $\mu \mathrm{m}$ and $160 \mu \mathrm{m}$ long, respectively, tibial comb present, with 7 long bristles. Lengths and proportions of legs as in Table 1.

Hypopygium (Figure 1A). Tergite IX each side with a tuft of 45 strong setae. Gonocoxite $353 \mu \mathrm{m}$ long. Superior volsella clavate with 18-24 strong setae on ventral surface and 4-5 weak setae on the dorsal surface. Gonostylus bifurcate, main stem $208 \mu \mathrm{m}$ long, with a subapical lobe $133 \mu \mathrm{m}$ long, between two lobes, a darkbrown tubercle present. Ratio of subapical lobe/main lobe 0.64 . Apex of gonostylus with 4 stout lamelliform megasetae, 50-60 $\mu \mathrm{m}$ long, followed by 7-9 slender setae in the subapical $1 / 3,45-80 \mu \mathrm{m}$ long. No basal strong seta in the basal portion of gonostylus (before the lobe fork). HR 1.70; HV 3.60.

Pupa $(n=3)$.

Total length 6.7-7.6, 7.1 mm. Body length 4.7-5.6, $5.2 \mathrm{~mm}$.
COLORATION. Whole pupa yellowish brown, the chitinized scutal projections black.

Cephalothorax (Figure 1B). Thoracic horn 680-820, $744 \mu \mathrm{m}$ long, 50-90, $78 \mu \mathrm{m}$ wide, with weak spines in the middle swollen and apical slender parts. Basal half $(0.40-0.51,0.47)$ of male horn slightly swollen, unobvious or weak in female horn (Figure 1C), horn ratio $8.75-13.60,9.87$. The prominent chitinized thoracic projection truncated, 140-180, $160 \mu \mathrm{m}$ long and 130-160, $140 \mu \mathrm{m}$ in basal width. Thorax with two antepronotals, 70-90, $75 \mu \mathrm{m}$ and $110-150,130 \mu \mathrm{m}$ long, respectively. Each length of three precorneals (in $\mu \mathrm{m}$ ): 70-85, 79; 120-170, 145; 60-75, 66; Dorsocentrals inserted posteriorly, with $\mathrm{Dc}_{1}$ and $\mathrm{Dc}_{4}$ distinctly stronger than $\mathrm{Dc}_{2}$ and $\mathrm{Dc}_{3}$.

ABDOMEN (Figure 1D). Tergite II-VIII with posterior transverse band of alternatively arranged long spines and small spines, the number of long spines and the length of longest spine are listed in Table 2. Conjunctive only presents in T II/III, with 2-3 rows of weak hooklets, $0.71-0.80,0.74$ times as wide as corresponded segment width.

ANAL LOBE. 570-690, $610 \mu \mathrm{m}$ long, with distinct anterior median band. Anal lobe ratio 1.46-1.64, 1.56. Distal margin 1/5 with 4-5 strong, 480-620 $\mu \mathrm{m}$ long and 1 weak macrosetae, 280-450 $\mu \mathrm{m}$ long. The most 2 apical setae with minute lateral spine near subapical area. Male genital sac reaching as far as anal lobe tips or slightly beyond the tips, but distinctly shorter in the female. Furthermore, 2-3 tubercles clearly present at the subapical margin of female anal lobe (Figure 1E) but absent in the male.

\section{Larva $(\mathrm{n}=2)$.}

Total length 6.8-7.1 mm. Head capsule 520-540 $\mu \mathrm{m}$ long, and 390$400 \mu \mathrm{m}$ wide, cephalic index 0.74-0.75.

Coloration. Generally, the body is very fat and milk-white in color. Head capsule yellow. Apical part of mandible, whole mentum and premandible dark brown. Posterior occipital margin yellowish brown.

Dorsal surface of head capsule in Figure 2A. Labral sclerites arrangement resembles that observed in Brillia Kieffer, frons separated from clypeus, anterior margin with a clear pale membrane band, where a distinct tubular-based S3 seta placed. Labral sclerites fragmentary, at least split into 2 pairs, a small pair in the middle, and another in the lateral. Clypeal sclerites also split into 2 parts, S2 placed in the anterior sclerites, which somewhat interrupted in the middle. Lateral sclerite 1 and 2 absent, 3 complete. ANTENNA (Figure 2B). Antennal reduced, each segments length (in $\mu \mathrm{m})$ : 25-30; 10-13; 2-3; 4-5; AR 1.20-1.38. Basal segment 2.12-

Table 1. Lengths (in $\mu \mathrm{m}$ ) and proportions of leg segments of Eurycnemus cf. nozakii based on Chinese material.

\begin{tabular}{lccc} 
& $\mathrm{P}_{1}$ & $\mathrm{P}_{2}$ & $\mathrm{P}_{3}$ \\
$\mathrm{fe}$ & 1200 & 1425 & 1625 \\
$\mathrm{ti}$ & 1400 & 1400 & 1575 \\
\hline $\mathrm{ta}_{1}$ & 1050 & 700 & 950 \\
$\mathrm{ta}_{2}$ & 650 & 340 & 550 \\
\hline $\mathrm{ta}_{3}$ & 500 & 280 & 430 \\
$\mathrm{ta}_{4}$ & 450 & 200 & 300 \\
\hline $\mathrm{ta}_{5}$ & 270 & 180 & 210 \\
$\mathrm{LR}$ & 0.75 & 0.5 & 0.6 \\
\hline $\mathrm{BV}$ & 1.95 & 3.5 & 2.79 \\
$\mathrm{SV}$ & 2.48 & 4.04 & 3.37 \\
\hline
\end{tabular}




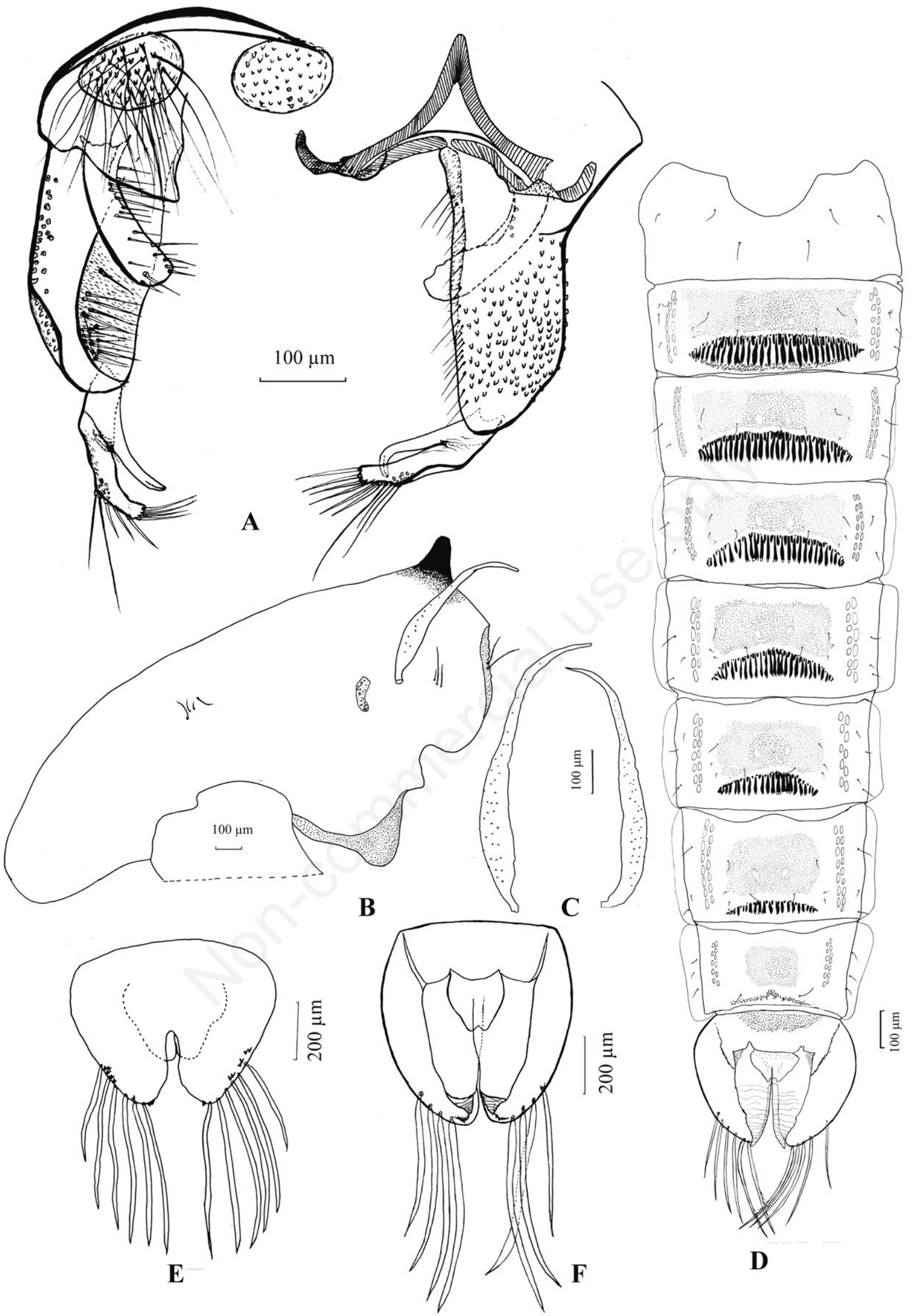

Figure 1. Eurycnemus cf. nozakii Kobayashi, A) male, B-F) pupa. A) hypopygium; B)thorax (lateral view); C) thoracic horn (left, male; right, female); D) pupal abdomen; E) details of female anal lobe, indicating the lateral spines; F) Anal lobe of $E$. sp., indicating the relative length of genital sac. 
2.40 times as long as width. Ring organ around in the middle.

LABRUM (Figure 2C). SI simple but lamella like, SII and SIII tightly placed, SIII minute, SIV a and SIV b vestigial, without clear pits. Labral lamellae with 2 slightly separated lobes or closely touched, giving appearance of a single comb, each lobe bearing 45 serrate teeth distally. Ungula with well-developed basal sclerite, 3 pairs of chaetulae laterals and 3-4 pairs of chaetulae basales present, all simple. Pecten epipharyngis with 2 or 3 isolated scales. Premandible $65-75 \mu \mathrm{m}$ long, with 2 fairly separately apical teeth and one pale basal tooth.

MANDIBLE (Figure 2D). Total length 125-150 $\mu \mathrm{m}$ long, with a shallow notch at apical 1/3; Seta subdentalis $35-43 \mu \mathrm{m}$ long, extending to the beneath of fourth inner tooth. Seta interna weak, with 4 simple branches.

Mentum (Figure 2E). Almost trapezoid, 105-120 $\mu \mathrm{m}$ wide, 90-93 $\mu \mathrm{m}$ high; centre median tooth 13-15 $\mu \mathrm{m}$ wide, shorter and lower than lateral median teeth, easy to broken. Ventromental plate present, $18-20 \mu \mathrm{m}$ in basal width; Distance between setae submenti 135-153 $\mu \mathrm{m}$. Postmentum 260-265 $\mu \mathrm{m}$ long.

BoDY. Procercus sclerotized laterally, $25 \mu \mathrm{m}$ high, $18 \mu \mathrm{m}$ wide $(\mathrm{n}=1)$, bearing 4 simple anal setae, usually 2 strong setae together with one median and one weak seta, 90-285 $\mu \mathrm{m}$ long, lateral setae minute, 60-70 $\mu \mathrm{m}$ long.

MATERIAL EXAMINED. 1 pharate male, CHINA: Liaoning province, Benxi City, Huanren County, Hunhe catchment, Suzi River, site H6, viii.2014, C.B. Duan 2 pupae and 1 larva with partial pupal character, as previous; 1 pupa and 1 larva, CHINA: Liaoning province, Benxi City, Xinbin County, Liaohe catchment, north branch of Taizi River, site T70, viii.2009, C.B. Duan.

Distribution. China (Liaoning Province).

BiologicAl NOTE. The material was collected from the upstream of Suzi and Taizi River, both of which are the headwaters. The conductivity ranges from 60 to $101 \mu \mathrm{s} / \mathrm{cm}$, and $\mathrm{pH}$ from 7.4 to 8.6. The co-occurring caddisflies are Goera interrogationis Botosaneanu, 1970 and Hydropsyche spp. No direct links between the midge larva and caddisfly pupa was observed. Thus, both of the above caddisflies are suspected here to be the host of E. cf. nozakii.

REMARKS. The Chinese species shows some differences to the Japanese population (Kobayashi, 1998). Some measures from the examined adult are slightly lower than that in the original description of E. nozakii, but the ratios, such as AR and LR are close to each other. However, the distinct hind tibial comb and absence of basal strong gonostylus seta in our species is distinct. In the pupa and larva, the longest pupal macrosetae are usually less than the anal lobe, conjunctive present only on T II/III, and the larval anal setae are simple, While, in true E. nozakii, the anal macrosetae usually longer than the length of anal lobe, conjunctive present on $\mathrm{T}$
II/III/IV, larval anal setae bifurcated at basal 1/3 (Kobayashi, 1998). In addition, the Russian specimens described as E. nozakii (Makarchenko \& Makarchenko, 2008) was soon changed into an unnamed species after the new material became available (Makarchenko \& Makarchenko, 2012). Some detailed comparisons among the Japanese, Far East of Russia and Chinese Eurycnemus are listed in Table 3. Perhaps, there are more sibling species in East Asia.

\section{Eurycnemus sp.}

Pupa $(n=3)$.

Total length 6.0-8.5, 7.5 mm. Body length 4.6-6.1, 5.4 mm.

Coloration. As above description.

Cephalothorax. Thoracic horn 600-980, $740 \mu \mathrm{m}$ long, 45-80, $59 \mu \mathrm{m}$ wide, with weak spines in the middle swollen and apical slender parts. Basal half $(0.32-0.53,0.43)$ of male horn slightly swollen, while, weak in female horn. Horn ratio 8.3-12.0, 10.5. The prominent chitinized thoracic projection truncated in the male while sharp in the female, 160-180, $170 \mu \mathrm{m}$ long and 90$100,95 \mu \mathrm{m}$ in basal width. Thorax with two antepronotals, 60-85, $73 \mu \mathrm{m}$ and 90-110, $100 \mu \mathrm{m}$ long, respectively. Each length of precorneals (in $\mu \mathrm{m}$ ): $85-90,88 ; 120-125,123$; 70-105, 88; Dorsocentrals inserted posteriorly, with $\mathrm{Dc}_{1}$ and $\mathrm{Dc}_{4}$ distinctly stronger than $\mathrm{Dc}_{2}$ and $\mathrm{Dc}_{3}$.

ABDOMEN. Tergite II-VIII with posterior transverse band of alternatively arranged long spines and small spines, the number of long spines and the length of longest spine are list in Table 2. Conjunctive only present in T II/III, with 2-3 rows of weak hooklets, $0.58-0.60,0.59$ times as wide as corresponded segment width.

ANAL LOBE. 575-675, $625 \mu \mathrm{m}$ long, without spinulation anteriorly. Anal lobe ratio $0.92-1.0,0.97$. Distal margin $1 / 5$ with 4 strong macrosetae, 490-620 $\mu \mathrm{m}$ long. Male genital sac shorter than anal lobe tips (Figure 1F), 3-7 tubercles clearly present at the subapical margin of female anal lobe, whereas no such structure found in the male.

Material eXamined. 1 Pe, China: Fujian Province, Wuyishan City, Wuyishan National Nature Reserve, Tongmu Country, Sangang, 05.viii.2014, H.Q. Tang \& J. Liu. 2 Pe, China: Yunnan Province, Ruili City, a brook in Municipal Botanical Garden, 25.x.2016, H.Q. Tang.

REMARKS. Except the shorter male genital sac and tergite IX without spinulations, there is no other substantial characters to separate the present pupal type from E. cf. nozakii. Since the locations are very far from each other and belong to different zoogeographic regions, pupal type collected from Oriental region (Fujian and Yunnan) are treated separately here.

Table 2. The number of long spines (the short basal small spine not counted) and length of longest spines in posterior transverse bands of tergite II to VIII in Chinese species Eurycnemus cf. nozakii and Eurycnemus sp.

\begin{tabular}{|c|c|c|c|c|}
\hline \multirow[t]{2}{*}{ Posterior band } & \multicolumn{2}{|c|}{ Eurycnemus cf. nozakii } & \multicolumn{2}{|c|}{ Eurycnemus sp. } \\
\hline & Number & Max length & Number & Max length \\
\hline T II & $30-35$ & $150-170$ & $32-33$ & $165-170$ \\
\hline T III & $28-30$ & $160-180$ & $30-31$ & $165-170$ \\
\hline T IV & $24-30$ & $160-170$ & $27-29$ & $150-160$ \\
\hline TV & $20-25$ & $150-170$ & $24-26$ & $140-160$ \\
\hline T VI & $18-24$ & $120-130$ & $22-23$ & $115-130$ \\
\hline T VII & $16-22$ & $50-80$ & $18-21$ & $65-80$ \\
\hline T VIII & $4-10$ & $25-30$ & 0 & 0 \\
\hline
\end{tabular}




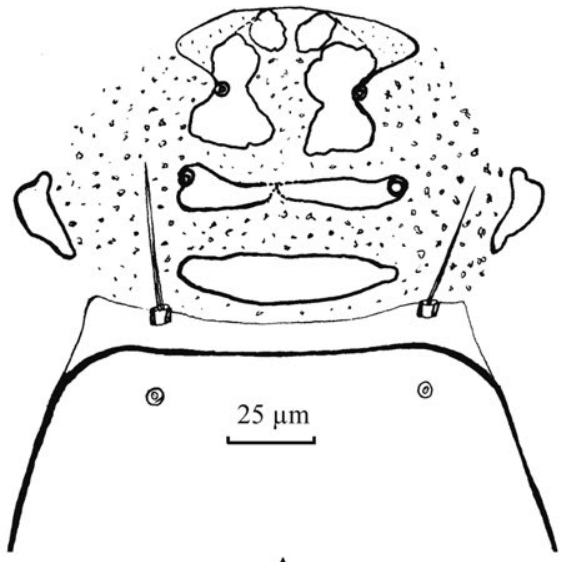

A

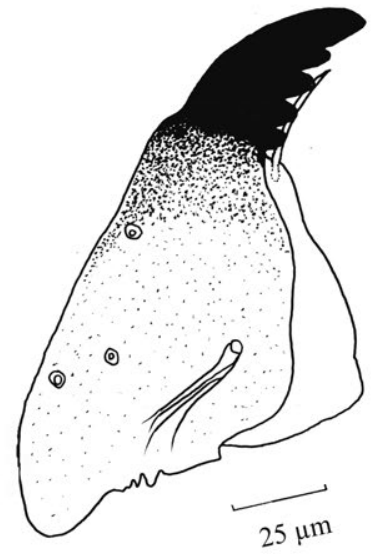

D

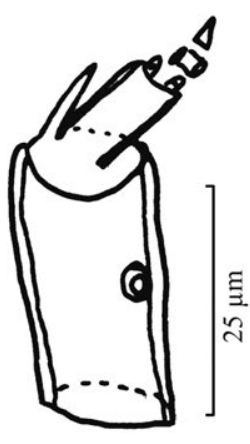

B

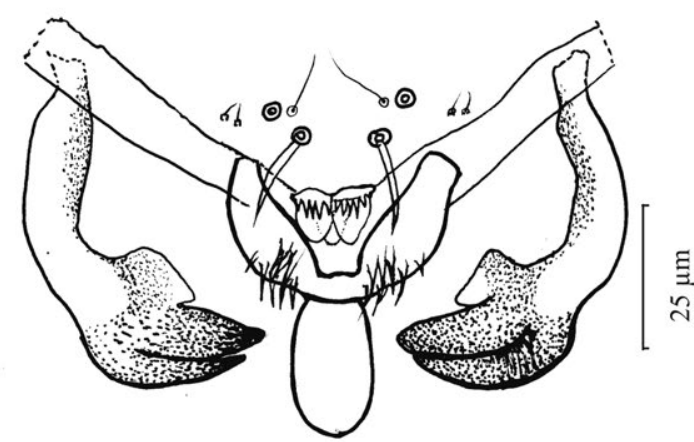

C

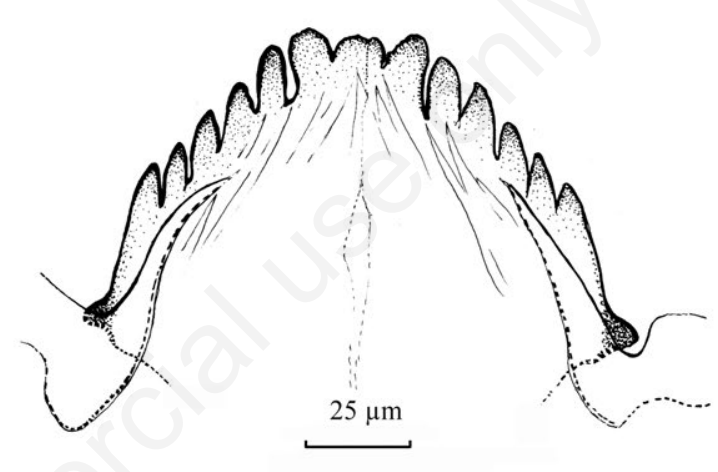

E

(๑)

Figure 2. Eurycnemus cf. nozakii Kobayashi, larva. A) dorsal sclerites of head capsule; B) antenna; C) labro-epipharyngeal region; D) mandible; E) mentum.

Table 3. Comparisons among Japanese, Far East of Russia and Chinese species of Eurycnemus cf. nozakii Kobayashi.

\begin{tabular}{|c|c|c|c|}
\hline Characters & Japanese & Russian FE & Chinese \\
\hline \multicolumn{4}{|c|}{ Pupa/pupal exuviae } \\
\hline Total length & $8.0-8.7$ & 7.1 & $6.7-7.6$ \\
\hline Horn length & $715-869$ & 670 & $680-820$ \\
\hline Anal lobe length & ca. 850 & $500-600$ & $570-690$ \\
\hline Anal lobe $(+)$ & Smooth & Smooth & With 2-3 spines \\
\hline Anal macrosetae & 4-8 & $6-7$ & $4-6$ \\
\hline Inner seta of anal lobe & Absent & Present & Absent \\
\hline \multicolumn{4}{|c|}{ Larva (IV instar) } \\
\hline Total length & $7.2-11.5$ & $4.5-7.2$ & 6.8-7.1 \\
\hline Head color & Yellow & Light-brown & Yellow \\
\hline Seta interna & Absent & Present & Present \\
\hline AR & $0.81-1.00$ & $1.20-1.44$ & $1.20-1.38$ \\
\hline Middle tooth of mentum & $\begin{array}{l}\text { Simple, subequal } \\
\text { in height }\end{array}$ & $\begin{array}{l}\text { Subdivided into } 4 \text { small teeth, } \\
\text { lower and wider }\end{array}$ & $\begin{array}{l}\text { Simple, lower than outermost } \\
\text { median tooth }\end{array}$ \\
\hline Anal seta & Bifurcated & Simple & Simple \\
\hline
\end{tabular}




\section{References}

ANDERSEN T., SÆTHER O.A., CRANSTON P.S., EPLER J.H., 2013 - 9. The larvae of Orthocladiinae (Diptera: Chironomidae) of the Holarctic Region - Keys and diagnoses. In: The larvae of Chironomidae (Diptera) of the Holarctic Region - Keys and diagnoses. - Insect System. Evol. Lund, Sweden: 189-386.

ASHE P., O'CONNOR J.P., MURRAY D.A., 2000 - Larvae of Eurycnemus crassipes (Panzer) (Diptera: Chironomidae) ectoparastic on prepupae/pupae of Hydropsyhce siltalai Dohler (Trichoptera: Hydropsychidae), with a summary of known chironomid/trichopteran associations. - Spixiana 23: 267-274.

ASHE P., O'CONNOR J.P., MURRAY D.A., 2015 - A review of the distribution and ecology of Buchonomyia thienemanni Fittkau (Diptera: Chironomidae) including a first record for Russia. - Eur. J. Environ. Sci. 5: 5-11.

CRANSTON P.S., OLIVER D.R., SÆTHER O.A., 1983 - 9. The larvae of Orthocladiinae (Diptera: Chironomidae) of the Holarctic region - Keys and diagnoses. - Ent. Scand. Suppl. 19: 149-291.

CRANSTON P.S., OLIVER D.R., SÆTHER O.A., 1989 - 9. The adult males of Orthocladiinae (Diptera: Chironomidae) of the Holarctic region - Keys and diagnoses. - Ent. Scand. Suppl. 34: 165-352.

COFFMAN W.P., CRANSTON P.S., OLIVER D.R., SÆTHER O.A., 1986 - 9. The pupae of Orthocladiinae (Diptera: Chironomidae) of the Holarctic region - Keys and diagnoses. Ent. Scand. Suppl. 28: 147-296.
HAYASHI F., KOBAYASHI T., 2000 - Commensal and parasitic chironomids of Japan. - Hyogo Fresh. Biol. 51/52: 281-303.

KOBAYASHI T., 1993 - Eurycnemus sp. (Diptera: Chironomidae) ectoparasitic on pupae of Goera japonica (Trichoptera), newly recorded in Japan. - Jpn. J. Sanit. Zool. 44: 401-404.

KOBAYASHI T., 1995 - Eurycnemus sp. (Diptera: Chironomidae) larvae ectoparasitic on pupae of Goera japonica (Trichoptera: Limnephilidae). In: Cranston, P.S. (ed.). Chironomids: From genes to ecosystems. - CSIRO Australia, Victoria: 317-321.

KOBAYASHI T., 1998 - Eurycnemus nozakii sp. nov. (Diptera: Chironomidae), the second named Eurycnemus species. Entomol. Sci. 1: 109-114.

MAKARCHENKO E.A., MAKARCHENKO M.A., 2008 - New findings of chironomids (Diptera, Chironomidae) in Far East and bordering territories. V. subfamily Orthocladiinae. - Vladimir Ya. Levidanov's Biennial Memorial Meetings 4: 187-195.

MAKARCHENKO E.A., MAKARCHENKO M.A., 2012 Immature stages of some Far-Eastern Orthocladiinae (Diptera, Chironomidae). - Evraziat. Entomol. Z. 11: 115-128.

MURRAY D.A., ASHE P., 1981 - A description of the larva and pupa of Eurycnemus crassipes (Panzer) (Diptera: Chironomidae). - Entomol. Scand. 12: 357-361.

SÆTHER O.A., 1980 - Glossary of chironomid morphology terminology (Chironomidae: Diptera). - Entomol. Scand. 14: 1-51.

YANG L.F., SUN C.H., WANG B.X., MORSE J.C., 2003 - Present status of Chinese Trichoptera, with an annotated checklist. Proceedings of the 11th International Symposium on Trichoptera. Tokai University Press, Kanagawa: 441-465. 